National Institute of Rural Development ADVT 


\section{Price Trends in India and Their Implications for Measuring Poverty}

National Sample Survey data on the unit values of a large number of foods can be used to compute price index numbers that can be compared with the official national price indices, the Consumer Price Index for Agricultural Labourers for rural India, and the Consumer Price Index for Industrial Workers for urban India. This paper finds that over the five years from 1999-2000 to 2004-05, the food component of the CPIAL understated the rate of food price inflation. This understatement can be attributed to the use of long outdated weights (from 1983), and the resultant over-weighting of cereals, whose prices fell relative to other foods. The overall weight of food in the CPIAL is also too large, so that the growth in the general CPIAL was understated during this period when food prices fell relative to non-food prices. Under conservative assumptions, the paper calculates that the five-year growth in the reported CPIAL of 10.6 per cent should have been 14.3 per cent. The nominal poverty lines are also understated. As a result, and ignoring other problems with the counts, the official poverty ratio of 28.3 per cent for rural India in 2004-05 should be closer to 31 per cent; at current rates of rural poverty reduction, this eliminates more than three years of progress.

I am grateful for comments and assistance to Montek Singh Ahluwalia, K L Datta, Jean Drèze, Himanshu, Reetika Khera, Rinku Murgai, Abhijit Sen, Pronab Sen, Suresh Tendulkar, and Thu Vu. The views expressed here are entirely my own.

Angus Deaton (deaton@princeton.edu) is at the Woodrow Wilson School of Public and International Affairs and the economics department of Princeton University.
$\mathrm{T}$ The purpose of this paper is to compare the behaviour over time of the food components of the official Indian price indexes, the Consumer Price Index for Agricultural Labourers (CPIAL) and the Consumer Price Index for Industrial Workers (CPIIW) with food price indexes based on the unit values of foods collected in the various rounds of the National Sample Survey (Nss). This comparison is of interest in its own right, partly to check the official numbers - the CPIAL and CPIIW are important price indexes with many uses - and partly to investigate the strengths and weaknesses of using the unit value data to construct price indexes.

My findings indicate that if the survey numbers are correct, the rate of inflation in food prices from 1999-2000 to 2004-05 was almost 70 per cent higher than shown by the food component of the CPIAL, a finding that is at least in part attributable to overweighting of cereals within the CPIAL food index. Over the same period, inflation in the overall (general) CPIAL index appears to be understated by a little more than 40 per cent, in part because of the understatement of its food component, and in part because the CPIAL attaches a weight to food that is almost 9 percentage points too high, so that when food prices rise less than other prices, as happened between 1999-2000 and 2004-05, the general index rises too slowly. Errors in the CPIIW are in the same direction, but are much smaller.

One of the many roles of the CPIAL and CPIIW price indexes is in measuring poverty rates. Indian poverty lines are held constant in real terms, and are updated over time using versions of the CPIAL and CPIIW that are re-weighted to reflect the higher than average share of food among those close to the poverty line; more precisely, and according to the recommendations of a 1993 Expert Group, government of India (1993), the food and non-food components of the two indexes are re-weighted using average food shares of households near the poverty line in 1973-74, shares that are very much larger than the food shares of households near the poverty line in recent years. The nominal poverty lines so calculated are then used to calculate the fractions of people living in households with reported nominal per capita expenditures that fall below the lines. Any errors in the components of the CPIAL or CPIIW carry through into the estimated poverty rates. When I update the all India rural poverty line to match my revised price indexes, bur retaining the expert group's weights for food and non-food, the rate of rural poverty in 2004-05 is increased from the official figure of 28.3 per cent of the population to 31.1 per cent of the population, an increase of 2.8 percentage points. When I replace the expert group's food shares for 
households near the poverty line with more recent poverty-line food shares, the poverty headcount ratio rises a further one percentage point, to 32.1 per cent of the population. A disaggregated, state by state analysis, which comes closer to replicating the Planning Commission's own calculations, suggests a somewhat smaller discrepancy with the official poverty rates too low by 2.7 percentage points once all adjustments are made; at current rates, this is equivalent to the removal of more than three years worth of rural poverty reduction. Because food prices have fallen relative to non-food prices since 1999-200o, the use of outdated weights, which overstate the fraction of the budget spent on food, even for those near the poverty line, effectively short-changes the poor by assigning to them a price index that rises less rapidly than the cost of living based on their actual expenditure patterns.

It is important to emphasise that this paper addresses only one of the many problems besetting the current Indian poverty lines. While the poverty lines are certainly affected by possible errors in measured inflation, they are also based on a set of state and sectoral price indexes that are at best outdated, and at worst simply incorrect. Beyond that, India's poverty measures, like those of many other countries, are threatened by the effects of the long unresolved and still increasing discrepancy between the surveys and the national accounts [Deaton 2005].

Survey-based price indexes have been calculated a number of times in the past. Recent examples are Deaton and Tarozzi (2006), who calculated price indexes for 1993-94 relative to 1987-88, and Deaton (2005) who updated the estimates to include the 55th round data for 1999-200o. For those two comparisons, rural and urban rates of inflation in Laspeyres price indexes based on food and a few other items (tobacco, alcohol, and some fuels) were very similar to the overall rates of inflation in the all-India CPIAL and CPIIW indexes. The period since 1999-2000, particularly from the end of 1999 to early 2001, was unusual in recent Indian history in that food prices were either stationary (CPIIW) or falling (CPIAL). The task of computing price indexes is more difficult in such a period than in a period when the individual prices are dominated by a common upward trend. When each price is the sum of a common trend and an idiosyncratic component, the latter is readily identified and robustly measured, in spite of measurement error or uncertainty about the choice of weights. The same is not true in the absence of the trend. So the recent period is a particularly important one in which to check the official indexes. It should also be noted that, in recent years, there have been pronounced changes in Indian consumption patterns, with food becoming less important, and cereals becoming less important within food. At such times, regular updating of weights becomes important for price indexes, especially when the relative price of foods and non-foods has changed.

In Section 1, I explain the general procedures and the use of the survey data. In Section 2, I compare the all India CPIAL and CPIIW indexes over time, focusing on the periods 1983, 1987-88, 1993-94, and 1999 to mid-2005, which are the dates covered by the 38 th, $43 \mathrm{rd}$, 5oth, and 55 th through 61st rounds of the NSs. In contrast to the earlier periods, the food component of the CPIAL rises less rapidly than the surveys show should be the case; from 1999-2000 to 2004-05, the price index of food-based on what rural households report having paid rose by 4.5 percentage points more than did the food component of the CPIAL. Since there was little increase in food prices over this period, and if the survey numbers are to be treated as correct, the true rate of rural food price inflation from 1999-2000 to 2004-05 was two-thirds as high again as shown in the official statistics. The urban difference is in the same direction but much smaller. The surveys do not provide prices for non-foods, so I combine the inflation rates from the survey-based food price indexes with the inflation rates in the non-food component of the CPIAL. Because the weight of food in the CPIAL is less than one, the gap between the survey-based and CPIAL food indexes is diminished in the general index, but this is offset by the fact that the CPIAL assigns too large a weight to food in a period when food prices have risen less than non-food prices. As a result, the increase in the general CPIAL is understated by almost as much as is the increase in its food component.

Section 3 discusses the implications of the price indexes for the measurement of poverty, first using a short-cut All India methodology, and then state by state for the 17 largest states.

\section{Methods}

I use data from the most recent "large" Nss rounds, the 38th in 1983, the 43rd in 1987-88, the 5oth in 1993-94, the 55th in 1999-2000, and the 61st in 2004-05, together with the smaller rounds 56 through 60 , which fill in the period from mid-20oo to mid-2004. The 56th round ran from July 2000 to June 2001, the 57th from July 2001 to June 2002, the 58th from July 2002 to December 2002, the 59th through the calendar year 2003, and the 6oth from January to June 2004. In each of these surveys, using questionnaires that have varied over time, but were close to identical from the 55th through the 61st rounds, a single household respondent provides details of food purchases - both expenditures and physical quantities - on several hundred items. The ratio of expenditure to quantity provides a measure of price paid per unit for each good purchased by each household, and it is these "unit values" that I combine into food price indexes. Since I am working with prices over time, I compute chained indexes, so that each (large) survey provides the weights for the price index comparing it to the subsequent survey; for the "thin" rounds, 56 through 6o, as for the 6ist round itself, I use weights from the 55 th round. Although changes in the questionnaire design have typically been incremental - an exception is the 5oth round which was unique in distinguishing every possible good that might ever have been sold through the public distribution system (PDS) - the differences accumulate over time, so that the lists of foods in the 38th and 61st rounds have substantial differences. Chaining helps deal with this by comparing like with like and maximises comparability over time. It is also generally recommended because it allows adaptation to changing spending patterns over time. Indian consumption patterns have shown major changes over the last 25 years - food is less important in the overall budget, and cereals are less important within food - so that it makes little sense to measure current 
patterns of price change using consumption bundles that have long been abandoned.

\section{Special Problems of 55th Round}

There are special problems with the use of the 55th round, which used two reporting periods for many goods, a design which had not been used previously and has not been used since. While there have been many attempts to correct the expenditures and poverty estimates from this round, none has commanded general assent, and many commentators now choose to ignore the poverty estimates based on those data. However, these objections do not carry through in any obvious way to the use of the unit value data. For the food component of the survey - which is what concerns me here - the 55th round questionnaire asked respondents to report expenditures and quantities, for both the last 30 days and for the last seven days. As previous experimentation had shown, the seven-day period generates larger rates of consumption than at 30 days, at least for most goods, and there is a lasting concern that the presence of the seven-day questions caused respondents to report higher flows at 30 days than would have been the case without the dual response period. Comparison with early rounds, which contained only the 30-day questions, would thus overstate the decline in poverty. Even if this is correct, there is no reason to suspect contamination of the reported unit values, here taken from the 30-day reports, which appear to behave in the same way as earlier unit values - with many households reporting the same prices for the same items. And while expenditures in the 55th round may not be comparable to expenditures in other rounds, their only use in the food price index is as weights, which are scaled to sum to unity over all foods. So there is no obvious reason to distrust either the weights or the unit values from this large survey, at least as far as the construction of a food price index. When I construct an overall index, which requires a weight for food as a whole, it will be important to remember that this share might be overstated in the $55^{\text {th }}$ round.

A more general question is whether the unit values in the survey can be treated as prices. I and my coauthors have investigated this elsewhere, and the interested reader can consult Deaton and Tarozzi (2006), Deaton (1997, Chapter 5.1) and Deaton, Friedman, and Alatas (2005). In brief, and although richer consumers pay more per unit for some goods, the effects are generally small. For most of the important foods, we find that large fractions of households report the same unit values, at least within a sector or a single survey, and that those unit values closely match the corresponding prices collected by statistical agencies in markets and shops. Variations in quality are of course also a problem for standard indexes such as the CPIAL and CPIIW, where it is not always possible for price collectors to find exactly the same quality of an item in all locations and at all times. Yet it remains possible that the official indexes are doing a relatively good job of controlling for quality compared with the unit values, in which case rising real incomes might have generated a gradual upward shift in average quality over time in the unit values. If so, the survey indexes will spuriously drift upwards over time relative to the CPIAL and CPIIW.
In any given survey from period $t$, and each good $i$, I calculate the median unit value over all households purchasing the good, within sectors, and in the state by state analysis, within sectors of each state. The use of the median for the unit values - as opposed to the mean, for example - is to limit the effects of outliers, for example through the incorrect reporting of units. Even so, the ratios of prices from two surveys are closely examined good by good in order to detect and remove clearly absurd estimates; there are a few of these, typically for goods that are consumed only by a few households, where the units are not clear or possibly variable (e g, fruit juice, cake or pastry, cold beverages), or where the definition of the good permits a range of items (e $g$ other dried fruits, or other milk products). I write $\mathrm{p}_{\text {it }}$ for the median unit value, and $\mathrm{s}_{\mathrm{it}}$ for the corresponding share of the good in all food expenditures. This is computed by calculating the shares for each household, and then averaging over all households including those households with a zero share for the good. Because the shares lie between zero and one, there is less of a problem of outliers than with the unit values, and means, unlike medians, preserve the adding up properties that we need when using the shares as weights for index numbers.

\section{Laspeyres Index}

I shall focus on the Laspeyres index for period 1 based on period $\mathrm{o}$, where $\mathrm{o}$ and 1 typically refer to adjacent surveys. There are good arguments for considering other price indexes, particularly superlative indexes, such as Fisher's ideal index, which take some account of the fact that consumers adapt their behaviour to changes in relative prices. But my purpose here is to calculate price indexes that are comparable in spirit to the CPIAL and CPIIW, which are both base-weighted indexes of the Laspeyres type. Even so, the CPIAL and CPIIW update their weights only irregularly (the CPIAL currently uses 1983 weights, and the CPIIW weights are even older, or at least were so until late 2005), whereas the Laspeyres indexes here are chained, updating weights with every large round of the expenditure survey. I maintain this distinction because the lack of regular updating in the official indexes is a design flaw; using outmoded expenditure patterns to measure current inflation is best regarded as an error that is likely to have serious consequences when expenditure patterns are changing quickly and relative prices are changing. One of my concerns here is to quantify the size of that error. Given that large rounds of the Nss are available every five or six years, regular re-weighting of the official price indexes could readily be accomplished without the collection of new data.

The Laspeyres index can be written as

$$
P_{10}^{L}=\sum_{i=1}^{n} s_{i 0} \frac{p_{i 1}}{p_{i 0}}
$$

I note finally the procedures used to deal with goods sold through the PDS, of which wheat/atta, rice, and sugar are the most important foods. From the 5oth round on, the Nss surveys treat goods bought through the PDs as distinct from the same goods bought through the market, and collect data on quantities and expenditures on each. In recent years, when the rules of access to the PDs have changed, with households above the 
poverty line excluded in principle, it is important to allow for the effects on the prices paid by consumers. For example, if rice from the PDS sells for Rs 5 per kilo, when the market price is Rs 11, but a substantial number of households are excluded from the former and shifted to the latter, the effective price rises, even though neither the PDS nor market price has changed. In order to accommodate this, I calculate a single price each for wheat, rice, and sugar, calculated as a weighted average, weighted by mean shares on PDS and market, of the median prices in the PDS and the market. The official CPIAL uses a similar procedure, though it collects data on availability from the same fair price shops used to sample prices, rather than from households, and it is unclear from where they obtain data for market purchases, see government of India (1996).

\section{All India Comparisons of Food Indexes}

Table 1 shows urban and rural chained Laspeyres food price indexes from the surveys in comparison to the food components of the CPIAL and the CPIIW. I have arbitrarily taken the 55th round (1999-2000) as 100, and scaled the other indexes to match. Note that this does not contradict the chaining for the survey-based indexes, where the 38th is base for the 43rd, the 43rd for the 5oth, the 5oth for the 55th, and the 55th for the later surveys. Up to 1999-200o, the survey-based and official food price indexes closely match one another; relative to 1999-2000, the two rural indexes were 28.16 per cent (survey) and 28.03 per cent (CPIAL), while the two urban indexes were 25.22 per cent (survey) and 25.09 (CPIIW).

After 2000 things are different. Note first that rural food prices were lower in 2000-ol compared with 1999-2000, for both the CPIAL and the survey index; according to the monthly data for the CPIAL food index, the fall began at the end of 1999 and continued until early 2001. The food component of the cPIIw is only slightly higher in 2000-ol than in 1999-2000, by o.8 per cent, and the monthly data show a fluctuating series without trend during the period from end 1999 to early 2001. During this time, the surveybased food price index does not decline by as much as does the

Table 1: Food Price Indexes, All-India, 1983 to 2004-05 $(1999-2000=100)$

\begin{tabular}{|c|c|c|c|c|c|c|}
\hline \multirow[b]{2}{*}{ Round Dates } & \multicolumn{2}{|c|}{ Rural India } & \multicolumn{2}{|c|}{ Urban India } & \multicolumn{2}{|c|}{1983 (38th Round) Weights } \\
\hline & $\begin{array}{l}\text { Survey-based } \\
\text { Food Index }\end{array}$ & $\begin{array}{l}\text { CPIAL } \\
\text { Food }\end{array}$ & $\begin{array}{c}\text { Survey-based } \\
\text { Food Index }\end{array}$ & $\begin{array}{r}\text { CPIIW } \\
\text { Food } \\
\end{array}$ & Rural & Urban \\
\hline 38 January to December 1983 & 28.16 & 28.03 & 25.22 & 25.09 & 27.95 & 26.38 \\
\hline 43 Jul y 1987 to June 1988 & 36.52 & 35.29 & 34.16 & 34.87 & - & - \\
\hline 50 Jul y 1993 to June 1994 & 63.82 & 62.50 & 61.47 & 62.17 & - & - \\
\hline 55 Jul y 1999 to June 2000 & 100 & 100 & 100 & 100 & 100 & 100 \\
\hline 56 July 2000 to June 2001 & 98.77 & 95.33 & 98.81 & 100.80 & 98.10 & 98.74 \\
\hline 57 July 2001 to June 2002 & 101.71 & 96.89 & 101.57 & 104.03 & 99.75 & 100.97 \\
\hline 58 July 2002 to December 2002 & 2105.40 & 100.19 & 106.56 & 107.24 & 103.44 & 105.40 \\
\hline 59 January to December 2003 & 104.58 & 102.68 & 106.60 & 108.88 & 102.21 & 105.27 \\
\hline 60 January to June 2004 & 109.35 & 103.53 & 109.51 & 110.38 & 106.52 & 108.00 \\
\hline 61 July 2004 to June 2005 & 111.21 & 106.67 & 113.90 & 112.88 & 108.49 & 112.44 \\
\hline
\end{tabular}

The survey based food indexes are chained Laspeyres indexes, using the large rounds $(38,43,50$, and 55$)$ as base to calculate price levels in each subsequent round. For Rounds 56 through 61 , the 55 th round is used as base. The food components of the CPIAL and CPIIW are calculated by averaging monthly values over each round, and then scaling to be 100 in the 55th round. I was unable to locate the monthly CPIIW food indexes for July 1983, for August through November 1987, and for June 1988; these missing values were replaced by linear interpolation. The series was complete for all rounds from the 50th on. Columns (5) and (6) are rural and urban Laspeyres indexes using the unit values from the surveys but based on 38th round weights and scaled to be 100 in 1999-2000. The last two column show indexes from 55 th to 61 st round with chaining throughout, so that the 55 th provides the weights for the 56 th, the 56 th for the 57 th, and so on. food component of the CPIAL, to only 98.77 compared with 95.33 per cent, opening up a more than three point difference between the two indexes. By the 61st round, in 2004-05, this gap is nearly five points, with an additional widening between the two series in early 2004. Because food price inflation was generally low from 1999-2000 to 2004-05, 6.7 per cent according to the CPIAL, and 11.2 per cent according to the survey-based indexes, the discrepancy is very large in ratio terms, with the survey-based index showing a rate of food price inflation that is two-thirds higher.

For the urban price indexes, the gap is originally in the opposite direction, with the survey-based index, like its rural counterpart, showing a small decline in prices, compared to a small increase in the food component of the cPIIw. By the end of the period, and comparing 2004-05 with 1999-2000, the two series are very close, 113.9 for the survey index relative to 112.9 for the food component of the cPIIw.

I have only limited information on the construction of the CPIAL and CPIIW, and in particular do not have access to the raw price information on which they are based. In consequence, I can only speculate about the sources of the discrepancies between them and the survey-based indexes shown here. The most obvious candidate is the use of outdated weights. The CPIAL is based in 1986-87, and uses weights from the 38th round of the Nss, which refers to calendar year 1983. The most notable change in expenditure patterns since 1983 is the fall in the share of cereals in total expenditure; averaged over households, rice and rice products took up 21.o per cent of the rural budget in 1987-88, but only 16.1 per cent in 1999-2000 (which may be an overestimate), and indeed the share has fallen to 13.2 per cent in 2004-05. The corresponding declines are 9.2 per cent (1983), 7.3 per cent (1999-2000), and 6.6 per cent (2004-05) for wheat, and 7.7 per cent (1983) to 2.3 per cent (1999-2000), and 2.o per cent (2004-05) for coarse cereals and their products. As to rural price changes between the 55th and 56th rounds, which is one period in which the indexes diverge, the median price paid for rice held steady at Rs 10 per kilo, while that for wheat fell from Rs 7.5 to 7.0, with more substantial falls for coarse cereals, from Rs 7 to Rs 6 for bajra, jowar, and barley, and from Rs 6 to Rs 5 for maize. Given that the food CPIAL index uses a weight for coarse cereals that is almost four times as large as it ought to be, it substantially overstated the fall in prices between the two rounds. The effect is smaller in the CPIIW, because even in the early 1980s, only a small fraction of the budget was spent on coarse cereals (2.4 per cent in 1983), but I do not have a full explanation of why the two pairs of indexes behave so differently in rural and urban areas.

The use of outdated weights is unlikely to be the whole story, however. The fifth and sixth columns of Table i present Laspeyres indexes for the disputed period, using the same survey prices as in the chained indexes, but using constant 38 th round (1983) weights throughout. If weighting is the problem, the rural version of this index should look more like the food CPIAL than does the chained index in the first column, which is indeed what the table shows. The re-weighting, from 1999-2000 to 1983 weights, resolves most but not all of the difference between the surveybased food index and the food component of the CPIAL. In the 
period when food prices were falling, between 1999-2000 and 2000-01, the 1983-based survey index still falls by less than the CPIAL, by 1.2 per cent relative to 4.7 per cent, but by 2004-05, the 1983-based rural survey index is only 1.8 points higher than the food CPIAL, as opposed to 4.5 points higher for the 1999-2000based survey index in the first column. So we can attribute perhaps a little more than a half of the shortfall of the cPIAL food component to its outdated weights. Presumably the rest of the difference can be attributed to the fact that the CPIAL is also based on different prices from those reported in the surveys or to other differences in methodology, for example that the CPIAL uses different weights in different states, and then aggregates up to the all-India level.

The last two columns of Table 1 consider another variant of weighting, in which the chaining continues through to the end of the period so that, instead of retaining the 1999-200o weights for the subsequent rounds, I use the 55 th round for the 56 th, the 56 th through the 57th, and so on, up to the use of 6oth round weights for the 61st round. My main calculations used only the large rounds for weighting, and it might be argued that the thin rounds, whose main design is for other purposes, are not suitable for this task. Even so, these alternative indexes are useful because they take into account recent changes in consumption patterns, and because they cover a period in which there have been changes in access rules and pricing in the PDS, which are also likely to change consumption patterns. The continuation of the chaining further widens the gap between the survey-based and official food indexes, adding 2.3 percentage points to the rural index, and 1.6 percentage points to the urban index. I do not emphasise these results in the analysis below, but note that they suggest that my procedures are conservative, possibly understating the underestimation of both the official food indexes and the prevalence of poverty.

Another possible source of divergence between the survey indexes and the CPIAL is that the latter uses weights from the expenditure patterns of agricultural labourers, not from the population as a whole. In order to check this, I have recomputed the rural survey price indexes using as weights the average expenditure patterns for agricultural labourers in the Nss surveys. This changes the last figure in the first column from 111.21 to 110.42 , clipping nearly a point off the discrepancy. However, if I further match CPIAL procedures by moving away from democratic survey-based indexes (which use the average of the budget shares as weights) to plutocratic survey-based indexes (which use the expenditure patterns in the aggregate of all households), my price index goes up to 111.89 , close to the original survey-based index. (To complete the record, the plutocratic version of the all-household survey-based index is o.1o percentage points higher than the democratic index.) It is therefore unlikely that the survey-based indexes are too high either because of democratic weighting or because they do not focus exclusively on households of agricultural labourers.

For many purposes, including indexing of wages, we are interested in the general CPIAL, not just its food component. Since food is only a fraction of the total budget, the substitution of the survey-based food component for the food component of the
CPIAL will have less than a one for one effect on the general index. However, the overall index uses an outdated and overlarge weight for food as a whole which, in a time of falling relative prices of food, leads to a further underestimation of the index.

There is no survey-based index for non-food because the nss surveys collect quantity data only for foods and a few other items. So I simply adopt the non-food components of the CPIAL and CPIIW and combine them into new general, survey-based indexes. To see how this works, I introduce some notation.

Write $\tilde{P}$ for the survey-based general index, and $P$ for the general CPIAL or CPIIW, whichever is under consideration. I then write

$$
\tilde{P}=\tilde{s}_{f} \tilde{P}_{f}+\left(1-\tilde{s}_{f}\right) P_{n}
$$

where the subscripts $f$ and $n$ denoted food and non-food respectively. In (2), the non-food index is from the CPIAL and so does not have a superimposed tilde. The CPIAL also satisfies its own version of (2),

$$
P=s_{f} P_{f}+\left(1-s_{f}\right) P_{n}
$$

where the absence of tildes indicates the official statistics. If (3) is used to calculate the non-food index, and the result substituted into (2), we obtain, with some rearrangement,

$$
\tilde{P}-P=\tilde{s}_{f}\left(\tilde{P}_{f}-P_{f}\right)+\frac{s_{f}-\tilde{s}_{f}}{1-s_{f}}\left(P-P_{f}\right)
$$

Equation (4) shows that the difference between the survey-based general index and the CPIAL has two terms, one to do with the difference in the survey-based and CPIAL food indexes, a term that is weighted by the share of food in the survey, and a second, that is to do with the difference in the food share between the survey and the food weight in the CPIAL.

In the current case, both corrections to the price index act in the same direction; see Table 2 which summarises the calculations. The survey-based food index is larger than the

\begin{tabular}{|c|c|c|c|}
\hline Rural India & & Urban India & \\
\hline CPIAL food index & 106.7 & CPIIW food index & 112.9 \\
\hline CPIAL non-food index & 119.4 & CPIIW non-food index & 131.9 \\
\hline General CPIAL & 110.6 & General CPIIW & 121.1 \\
\hline Survey-based food index: rural & 111.2 & Survey-based food index & 113.9 \\
\hline CPIAL food weight & 0.6915 & CPIAL food weight & 0.5700 \\
\hline 55 th round average food share & 0.6207 & 55th round average food share & 0.5384 \\
\hline Survey-based general index & 114.3 & Survey-based general index & 122.2 \\
\hline Expert group food weight & 0.8128 & Expert group food weight & 0.7463 \\
\hline Poverty line food weight from R55 & 0.6508 & Poverty line food weight from R55 & 0.5963 \\
\hline Expert group price index & 109.1 & Expert group price index & 117.7 \\
\hline With adjustment for food index & 112.7 & With adjustment for food index & 118.5 \\
\hline $\begin{array}{l}\text { With food index and food weight } \\
\text { adjustments }\end{array}$ & 114.1 & $\begin{array}{l}\text { With food index and food weight } \\
\text { adjustments }\end{array}$ & 121.2 \\
\hline
\end{tabular}
CPIAL food index, 111.3 to 106.7 , and this difference gets multiplied by the average food share in the rural 55 th round, which is

The first panel of CPIAL and CPIIW are the official numbers. The second panel is taken from Table 1. The third pane of weights are from the documentation of the CPIAL or from my calculations. The survey-based general indexes are the weighted averages of the survey-based food indexes in panel two and the CPIAL non-food index in panel 1 using the 55th round average food share in panel 2. The Expert Group food weight comes from government of India (1993, Table AIV1) and the poverty line food weight from R55 are my calculations from regressing the food share on the logarithm of per capita household total expenditure and its square, and evaluating the prediction at the poverty lines. In the final panel, the Expert group price index is the weighted average of the food and non-food components of the CPIAL and CPIIW using the food weights in panel 5. The second index using Expert Group weights, but the survey-based food price index in place of the CPIAL or CPIIW food component. The third index does the price index replacement and also uses the poverty line food weight from R55 in place of the Expert Group food weight. 
0.6207. The weight of food in the CPIAL is 0.6915 - because the CPIAL uses a 1983 food share - so that the second term is also positive. Taking all terms together, I finish up with a general CPIAL of 110.6 - from the official statistics - and a corrected general survey-based index of 114.3. As is to be expected, the corresponding correction to the general CPIIW is smaller, from 121.1 (official) to 122.2 (survey-based).

\section{Three Reasons}

There are three reasons why these corrections to the general indexes are likely to be understated. The first is the chaining argument already given; I stop chaining my survey-based indexes in 1999-2000, so that they take no account of changes in demand patterns in the subsequent five years. The second argument notes the general supposition that the unique questionnaire in the 55th round resulted in exaggerated 30-day reports of food. If so, the resulting food weight, which I use to combine the survey-based food index with the official non-food indexes, is too high. Substitution of a lower food weight would cause further divergence between the survey-based and official indexes. Third, the food weights from the 55th round that I use are democratic weights, computed by averaging each household's food share. The CPIAL,

\section{Table 3: Price Indexes 2004-05 vs 1999-2000, Poverty Lines and Headcount Ratios in 2004-05: Rural India}

\begin{tabular}{|c|c|c|c|c|c|c|c|c|c|}
\hline State & $\begin{array}{l}\text { Survey-Based } \\
\text { Food Index } \\
\text { (1) }\end{array}$ & $\begin{array}{l}\text { CPIAL } \\
\text { Food } \\
(2) \\
\end{array}$ & $\begin{array}{c}\text { Survey-Based } \\
\text { General Index } \\
\text { (3) }\end{array}$ & CPIAL & $\begin{array}{c}\text { Official } \\
\text { Poverty Lines } \\
\text { (5) }\end{array}$ & $\begin{array}{l}\text { Headcount } \\
\text { Ratio Official } \\
\text { (6) }\end{array}$ & $\begin{array}{l}\text { HCR Official } \\
\text { Recalculated } \\
\text { (7) }\end{array}$ & $\begin{array}{l}\text { HCR Adjusted } \\
\text { Food Price } \\
\text { Index } \\
(8)\end{array}$ & $\begin{array}{l}\text { HCR Adjusted } \\
\text { Food Price Index } \\
\text { and Weight } \\
\text { (9) }\end{array}$ \\
\hline Jammu and Kashmir & 109.0 & 102.7 & 113.5 & 107.8 & 391.26 & 4.3 & 4.3 & 5.9 & 6.4 \\
\hline Himachal Pradesh & 108.6 & 104.1 & 113.3 & 110.5 & 394.28 & 10.5 & 11.1 & 12.5 & 13.4 \\
\hline Punjab & 114.9 & 112.9 & 113.9 & 112.9 & 410.38 & 9.0 & 8.9 & 9.4 & 9.3 \\
\hline Haryana & 115.0 & 112.7 & 117.0 & 115.2 & 414.76 & 13.2 & 13.5 & 14.2 & 14.3 \\
\hline Rajasthan & 103.8 & 106.5 & 110.2 & 111.6 & 374.57 & 18.3 & 19.1 & 17.4 & 19.2 \\
\hline Uttar Pradesh & 108.7 & 107.3 & 113.6 & 111.9 & 365.84 & 33.3 & 34.1 & 34.9 & 36.7 \\
\hline Bihar & 105.9 & 103.6 & 111.0 & 108.0 & 354.36 & 42.6 & 43.2 & 45.1 & 47.0 \\
\hline Assam & 105.3 & 102.2 & 110.4 & 107.5 & 387.64 & 22.1 & 22.8 & 24.5 & 25.1 \\
\hline West Bengal & 107.5 & 104.1 & 114.4 & 109.7 & 382.82 & 28.4 & 28.2 & 30.9 & 32.6 \\
\hline Orissa & 97.6 & 95.7 & 105.3 & 101.2 & 325.79 & 46.9 & 46.9 & 48.3 & 51.0 \\
\hline Madhya Pradesh & 106.3 & 101.8 & 109.9 & 105.5 & 327.78 & 36.8 & 36.6 & 39.4 & 40.7 \\
\hline Gujarat & 115.8 & 108.3 & 118.5 & 112.9 & 353.93 & 18.9 & 19.2 & 22.8 & 23.1 \\
\hline Maharashtra & 112.3 & 111.1 & 116.8 & 115.3 & 362.25 & 29.6 & 29.7 & 30.4 & 31.6 \\
\hline Andhra Pradesh & 108.6 & 110.0 & 111.2 & 112.1 & 292.95 & 10.5 & 10.4 & 10.0 & 10.3 \\
\hline Karnataka & 105.2 & 101.3 & 110.8 & 107.6 & 324.17 & 20.7 & 22.2 & 25.2 & 26.8 \\
\hline Kerala & 109.1 & 116.8 & 106.7 & 112.4 & 430.12 & 13.2 & 12.7 & 10.2 & 10.1 \\
\hline Tamil Nadu & 110.9 & 111.5 & 115.6 & 115.1 & 351.86 & 23.0 & 22.9 & 22.7 & 23.6 \\
\hline All India & 111.2 & 106.7 & 114.3 & 110.6 & 356.30 & 27.3 & 27.6 & 28.7 & 30.0 \\
\hline
\end{tabular}

The survey based food index is calculated state by state according to the procedures described in the text. The all India number is taken from Table 1. The CPIAL food is calculated as the ratio of the averages of the monthly indexes for the 55th and 61st round. The CPIAL is the general index, again calculated as the ratio of the averages of the monthly indexes for the two rounds. The survey-based general index is a weighted average of the survey-based food index and the non-food component of the CPIAL, where the weights are the average food share over households in each state in the 55 th round; it is my current best estimate of what an updated general CPIAL should be. The poverty lines are the official poverty lines for the 61st round.

The official headcount ratios are my calculations of the fractions of persons in poverty using the official poverty lines; they differ slightly from the official calculations. The recalculated official headcount ratios are based on the 55th round poverty lines updated by my calculation of the price indexes used for the updating by the Planning Commission; there are reweighted versions of the CPIAL food and non-food using a set of food weights from the 1973B4 NSS and taken from the 1993 expert group report, Table AIV.1. The recalculated headcount ratios are typically close to the official ones.

The first adjusted headcount ratios also use the 55 th round poverty lines, and follow the expert group procedure as above. However, instead of using the food index of the CPIAL they use the survey-based food index in the first column.

The second adjusted headcount ratios follow the same procedure, using the survey-based food index, but instead of the Expert Group food weights from 1973B4, they use the food shares at the poverty line calculated from the 55 th round.

Given that the food shares in the 55 th round are likely to be overstated, and given that food prices have fallen relative to non-food prices, this procedure is conservative; lower food shares would generate higher headcount ratios.The final row of the table, for all-India, does not always correspond in any obvious way to the entries for the states.

In column (1), the all India survey-based index uses median unit values and average budget shares from all households, including those not residing in states in the table. Columns (2) and (4) show the all-India CPIAL food and general indexes, and column (3) is computed by combining the survey-based food price index with the non-food component of the CPIAL. The all India poverty line is calculated indirectly by finding the line which, when applied to the whole population, gives the same poverty rate as that obtained from combining the poverty rates for the individual states, including those not covered in the table. The all India implicit price index is the ratio of the all India poverty lines for the 61st and 55th rounds. The all-India adjusted poverty line in column (7) is the official all India poverty line multiplied by the ratio of the all India general CPIAL to the all India general survey-based index. The all-India poverty rate in the second to last column is from the official data, while the adjusted figure in the final columns is the weighted average over the states in the table; the population of these states comprises 92.4 per cent of the population of rural India. by contrast, uses a plutocratic weight from the 38 th round, which is the ratio of average food expenditure to average total household expenditure. According to my calculations the plutocratic food 3 Price Indexes and Measurement of Poverty

Indian poverty estimates are calculated using a set of poverty one fore and each sector. These were proposed large round to another, they are updated in nominal terms by a set of price deflators that are based on the state-specific CPIIW and CPIAL indexes. In order to make these indexes more relevant for people living near the poverty line, the food and non-food components of each index are re-weighted using weights that are listed in the Expert Group report. These are calculated from the 1973-74 round of the Nss, so that they are even more outdated than the weights in the CPIIW and CPIAL themselves, though they do have the advantage of being explicitly tailored to expenditure patterns near the poverty line. Even so, overweighting the share of food in a period where food prices are declining relative to other prices does no favour to people near the poverty line, because it leads to an underestimation of the increase in their cost of living.

I start with illustrative calculations based on the all-India poverty lines. These lines are "implicit" lines, which are defined as those all-India urban and rural lines which, when applied to all households in each sector, lead to the all-India headcount ratios that have been calculated by aggregating the state by state estimates. I shall reproduce something like the official calculations below, but start with the simpler calculation using the two all-India lines. Since there is little evidence of problems with price indexes prior to 1999-200o, I use the two poverty lines for the 55th round, which are 327.56 for rural and 454.11 for urban. 
Starting with the rural line, my calculation of the Expert Group's re-weighting of the CPIAL leads to an index of 1.091 from $55^{\text {th }}$ to 61st round, see Table 2 , which gives an all-India poverty line of 1.091 times 327.56 which is 357.37 , close to the 356.30 which is the all-India implicit poverty line for the 61st round. The "official" poverty rate according to my calculation is 28.5 per cent, close to the true official figure of 28.3 per cent. (All calculations and official figures for comparison are based on the 30-day uniform recall period.) If I repeat this calculation, again following the expert group procedure, and using their weights for food and non-food, but replacing the food component of the CPIAL with the survey-based food index, the price index for updating the lines is 112.7 , and the poverty rate rises to 31.1 per cent. Even this takes no account of the overestimation of the food share of the poor, set at 81.28 per cent. Using the 55 th round data, I regressed the share of food on the logarithm of household per capita total expenditure and its square, and used the resulting equation to predict food shares at the 55 th round poverty line. This gives a food share of 65.08 per cent; even the poor have reduced the share of their budget devoted to food over the quarter century between 1974-75 and 1999-200o! When I use 65.08 in place of 81.28 , and the survey-based food index in place of the CPIAL food index, the updating index rises to 114.1, and the estimated poverty rate rises to 32.5 per cent of the population, a full four percentage points higher than my replication of the official rate.

It should be noted that, even if there remain unresolved questions about the sources of the differences between the survey-based food price index and its CPIAL equivalent, there can be little defence for a poverty calculation that overstates by 16 points the food share of people at the poverty line, and thus understates the increase in the cost of living that they have recently faced.

As with the price indexes, the urban corrections are much smaller. My recalculation of the urban poverty-line price index is 117.70, which gives a 61st round all-India urban poverty line of 117.70 times 454.11 , which is 534.49 , compared with 538.6 in the official publications. This gives an urban poverty rate of 25.11 per cent, compared with the published rate of 25.62 per cent. Substituting the survey-based index for the cPIIw food index raises this to 25.58 per cent, and using both the survey-based index and the food share at the poverty line in the 55th round gives 26.86 per cent. Comparing this last with my version of the official count shows an underestimation of poverty in the latter by 1.75 percentage points.

These shortcut calculations are best treated as illustrative because the official procedures work at the state level, deriving the all-India estimates by aggregation. Here I repeat the calculations above for the 17 largest states, focusing entirely on the rural sector where the potential discrepancies are largest. The state by state calculations are of interest in their own right, and as we shall see the understatement of food inflation is replicated in most but not all states, and the size of the discrepancy varies from state to state.

The calculations are laid out in Table 3 (p 48). The first two columns show the survey-based and CPIAL food price indexes for
2004-05 relative to $1999-2000$ for each of the 17 largest states, as well as the all-India numbers previously discussed. In all states except Rajasthan, Andhra Pradesh, Kerala, and Tamil Nadu, the survey-based food price increase was larger than indicated by the state version of the CPIAL food index. In five states, Jammu and Kashmir (6.3 per cent), Himachal Pradesh (4.5 per cent), Madhya Pradesh ( 4.5 per cent), Gujarat (7.5 per cent), and Karnataka (3.9 per cent), the differences between the two indexes are substantial. The next two columns show the general CPIAL and the survey-based general index. The latter is calculated from the former and from the first two columns using equation (4) and the state by state average food shares from the 55th round survey as well as the weight of food in each state's CPIAL.

The official poverty lines are listed in the next column, followed by the official poverty rates and my recalculations of them. As before, I start from the 55th round poverty lines, and update following the Expert Group methodology using their state by state weights to combine the food and non-food components of the CPIAL. My versions of the official poverty rates are not identical to those published by the Planning Commission and shown in the previous column, but they are close, and their average over the 17 states, weighted by state populations, is 27.6 per cent, as opposed to 27.3 per cent.

The last two columns make two different adjustments. In the first, I substitute the state survey-based food index in column (1) for the CPIAL food index for the state, but otherwise maintain the Expert Group procedures. This shows the effect of recalculating the food index, but without reweighting. The all-India headcount ratio rises from 27.6 per cent to 28.7 per cent, and the state ratios mostly rise, except for the four states where the survey-based food index is lower than the food CPIAL. The last column shows the effects of modifying not only the food price index, but also the poverty line weights, substituting the poverty-line food shares for each state in the 55th round - calculated as above, but state by state - for the outdated weights used in the deflators for the official poverty lines. This takes the all-India headcount rate up to 30.0 per cent, an increase of 2.4 points from the base. Note that this increase is a good deal less than by the shortcut method, because the effects of the adjustments are different in different states, which have widely different headcount ratios.

\section{REFERENCES}

Deaton, Angus (1997): The Analysis of Household Surveys: A Microeconometric Approach to Development Policy, (World Bank).

(2003): 'Prices and Poverty in India, 1987-200o', Economic \& Political Weekly, January 25, pp 362-68.

- (2005): 'Measuring Poverty in a Growing World (or Measuring Growth in a Poor World)', Review of Economics and Statistics, 87(1), pp 1-19.

Deaton, Angus and Alessandro Tarozzi (2005): 'Prices and Poverty in India' Chapter 16 in Angus Deaton and Valerie Kozel, The Great Indian Poverty Debate, MacMillan, New Delhi.

Deaton, Angus, Jed Friedman, and Vivi Alatas (2004): 'Purchasing Power Parity Exchange Rates from Household Surveys', Research Programme in Development Studies, Princeton University, processed.

Government of India (1993): Report of the Expert Group on Estimation of the Proportion and Number of Poor, Planning Commission, New Delhi.

- (1996): Consumer Price Index for Agricultural Labourers in India: A Compendium, Ministry of Labour, Shimla/Chandigarh.

- (2007): 'Poverty Estimates for 2004-05', Press Information Bureau, New Delhi, March 21. 